\title{
AVALIAÇÃO DO CONHECIMENTO DA POPULAÇÃO E DOS PROFISSIONAIS DA SAÚDE SOBRE DOAÇÃO DE CÓRNEAS
}

\author{
Assessment on the population and health professionals' knowledge on the cornea donation process
}

Michele Aparecida Lonardoni Krieger ${ }^{1}$, Andrea Mora De Marco Novellino ${ }^{1}$, Ana Cláudia Munemori Mariushi², Hamilton Moreira ${ }^{3}$

\begin{abstract}
RESUMO
Introdução: O transplante de córneas é hoje o tipo mais comum de transplante de tecidos e vem crescendo a cada ano no Brasil. Há, entretanto, uma falta de doadores esclarecidos, conseqüência da desinformação por parte da população e dos profissionais da área da saúde. Objetivo: Avaliar o conhecimento da população leiga, dos profissionais de saúde e de médicos sobre o processo de doação de córneas, procurando identificar as possíveis falhas no processo de captação. Métodos: Durante a realização da Campanha de Doação de Córneas desenvolvida em Curitiba-PR, solicitou-se que médicos, profissionais de saúde e leigos respondessem a um questionário com perguntas subjetivas e de conhecimento sobre o tema Doação de Córnea. Resultados: No total, 588 pessoas responderam o questionário, sendo 313 leigos, 157 profissionais da saúde e 118 médicos. Desses, 94,4\% eram a favor da doação de córneas, sendo 91,3\% dos leigos, $96,1 \%$ dos profissionais da saúde e $100 \%$ dos médicos. Dos leigos, $83 \%$ doariam suas córneas frente a 83,4\% dos profissionais da saúde e 97,4\% dos médicos. Quando as perguntas subjetivas deram lugar a questões sobre conhecimento, observou-se uma alta taxa de dúvida entre os entrevistados. Questões como "limite de idade para a doação", "entendimento da função do banco de olhos" e "número de pessoas na fila do transplante" tiveram índices de indecisão de 95,8\%, 28,1\% e 64,8\%, respectivamente. Conclusão: Observou-se que ainda há pouca informação sobre o transplante de córneas, mesmo dentre médicos e profissionais de saúde. Sugere-se focar na profissionalização das equipes de abordagem a fim de aumentar a captação e o número dessa modalidade de transplante, além de estimular campanhas de conscientização da população.
\end{abstract}

Descritores: Córnea, Transplante de Córnea, Doação de Tecido, Conhecimento.

Instituições:
1 Departamento de Medicina da Pontifícia Universidade Católica - Curitiba / PR - Brasil
2 Departamento de Oftalmologia do Hospital de Olhos do Paraná - HOPR - Curitiba / PR -
Brasil
${ }^{3}$ Departamento de Oftalmologia da Universidade Federal do Paraná - UFPR - Curitiba / PR -
Brasil; Professor Titular da Faculdade Evangélica do Paraná - FEPAR - Curitiba / PR - Brasil

Correspondência:

Hamilton Moreira

Rua Coronel Dulcidio, 199 - $4^{\circ}$ Andar - Curitiba / PR - CEP: 80420-170 - Brasil

Tel.: (41) 33104224 / Fax: (41) 33104228

E-mail: elisazinher@hospitaldeolhosdoparana.com.br

\section{INTRODUÇÃO}

O transplante de córneas é hoje o tipo mais comum de transplante de tecidos, e vem crescendo a cada ano no Brasil. No entanto, o número de cirurgias realizadas é ainda pequeno em relação à demanda de pacientes à espera desse tipo de transplante.

Sabe-se hoje que o transplante de córnea constitui uma alternativa terapêutica cada vez melhor para grande parte de doenças corneanas. ${ }^{1}$ Porém, um dos principais obstáculos para melhorar esse panorama é a falta de doadores esclarecidos, conseqüência da desinformação por parte de profissionais da área da saúde e da classe médica, bem como entraves legais e religiosos. ${ }^{2}$

A disparidade existente entre o número de potenciais doadores e o número real de doações tem sido muito debatida. ${ }^{3-5}$ Conforme um estudo americano publicado em $1990,{ }^{6}$ em um número de 20.000 indivíduos que morrem por ano e considerados doadores em potencial, apenas 3.000 acabam doando as córneas. No Brasil, deparamos com uma situação muito semelhante, levando à conclusão de que esses dados parecem ser um reflexo, entre outras coisas, da falta de conhecimento ou, muitas vezes, noções errôneas por parte da população e profissionais de ambientes hospitalares.

A negativa de consentimento poderia ser contornada mais facilmente se os profissionais envolvidos no processo de captação 
esclarecessem de forma competente as dúvidas dos familiares. Observa-se, entretanto, que muitos profissionais não estão preparados para responder a questionamentos sobre a doação., ${ }^{4,7}$

Este estudo tem por objetivo avaliar o conhecimento da população leiga, dos profissionais de saúde e médicos a respeito de doações de córnea. Com a análise desses dados pretende-se buscar meios para melhorar o entendimento da população em geral sobre o processo de doação de córneas.

\section{MÉTODOS}

No segundo semestre de 2008, durante a semana do Dia Mundial da Visão, o Banco de Olhos do Hospital de Clínicas da Universidade Federal do Paraná, com o apoio do Conselho Brasileiro de Oftalmologia, organizou em Curitiba-PR uma campanha para divulgar a importância da doação de córneas. Durante esse ato, foram distribuídos panfletos explicativos e, às pessoas que consentiram, solicitou-se que respondessem a um questionário (Anexo 1) sob forma de entrevista.

\section{Anexo 1}

1. Questionário: População Leiga, Profissional da Saúde e Médicos

\begin{tabular}{|c|c|c|c|c|}
\hline 1. & Sexo: & ( ) masculino & ( ) feminino & \\
\hline 2. & Idade: & & & \\
\hline 3. & Profissão: & & & \\
\hline \multirow[t]{7}{*}{4.} & Escolaridade? & & & \\
\hline & a. ( )-primeiro grau incompleto & & & \\
\hline & b. ( )-primeiro grau completo & & & \\
\hline & c. ( )-segundo grau incompleto & & & \\
\hline & d. ( ) - segundo grau completo & & & \\
\hline & e. ( )-terceiro grau incompleto & & & \\
\hline & f. ( ) - terceiro grau completo & & & \\
\hline 5. & $\begin{array}{l}\text { Você é favorável a doação de } \\
\text { córnea? }\end{array}$ & ( ) Sim & ( ) Não & ( ) Não Sei \\
\hline 6. & Você doaria suas córneas? & ( ) Sim & ( ) Não & ( ) NãoSei \\
\hline 7. & $\begin{array}{l}\text { Você tem medo de ser um } \\
\text { doador? }\end{array}$ & ( ) $\operatorname{Sim}$ & ( ) Não & ( ) Não Sei \\
\hline 8. & $\begin{array}{l}\text { Autoriza a doação de um } \\
\text { familiar? }\end{array}$ & ( ) Sim & ( ) Não & ( ) Não Sei \\
\hline 9. & $\begin{array}{l}\text { Incentiva a doação entre pessoas } \\
\text { de suas relações? }\end{array}$ & ( ) Sim & ( )Não & \\
\hline 10. & $\begin{array}{l}\text { Você acha que a doação de } \\
\text { córneas modifica a aparência } \\
\text { do doador? }\end{array}$ & ( ) Sim & ( ) Não & ( ) NãoSei \\
\hline 11. & $\begin{array}{l}\text { Você sabe quantas pessoas } \\
\text { aguardam por um transplante de } \\
\text { córneas no Brasil? }\end{array}$ & ( ) Sim & ( )Não & \\
\hline 12. & Crianças podem doar? & $($ ) Sim & ( ) Não & ( ) Não Sei \\
\hline 13. & $\begin{array}{l}\text { Há necessidade de se ter a } \\
\text { mesma cor de olho do doador? }\end{array}$ & ( ) Sim & ( ) Não & ( ) NãoSei \\
\hline 14. & $\begin{array}{l}\text { Você sabe se existe um limite de } \\
\text { idade para ser um doador? }\end{array}$ & ( ) Sim & ( ) Não & ( ) NãoSei \\
\hline 15. & $\begin{array}{l}\text { Você sabe como proceder para } \\
\text { ser um doador? }\end{array}$ & ( ) Sim & ( )Não & \\
\hline 16. & $\begin{array}{l}\text { Você sabe o que é um banco } \\
\text { de olhos? }\end{array}$ & ( ) $\operatorname{Sim}$ & ( ) Não & ( ) Não Sei \\
\hline
\end{tabular}

2. Questionário Específico: Médicos

\begin{tabular}{|c|c|c|c|c|}
\hline 1. & $\begin{array}{l}\text { Você sabe até quanto tempo após o óbito } \\
\text { os tecidos oculares podem ser retirados? }\end{array}$ & ( ) Sim & （） Não & ( ) Não Sei \\
\hline 2. & $\begin{array}{l}\text { Você sabe quanto tempo dura o } \\
\text { procedimento de retirada das córneas? }\end{array}$ & ( ) Sim & （）Não & ( ) Não Sei \\
\hline 3. & $\begin{array}{l}\text { Você sabe onde podem ser retiradas as } \\
\text { córneas? }\end{array}$ & ( ) $\operatorname{Sim}$ & （ ） Não & ( ) Não Sei \\
\hline 4. & Já solicitou alguma doação? & ( ) Sim & （ ） Não & \\
\hline 5. & Sabe se há contra-indicação? & ( ) Sim & ( ) Não & ( ) Não Sei \\
\hline 6. & $\begin{array}{l}\text { Acha-se apto a responder as dúvidas de } \\
\text { uma possível doação? }\end{array}$ & ( ) Sim & （） Não & ( ) Não Sei \\
\hline 7. & Gostaria de saber mais sobre a doação? & ( ) Sim & ( ) Não & ( ) Não Sei \\
\hline
\end{tabular}

As entrevistas foram realizadas nos principais hospitais da cidade, a saber: Hospital de Clínicas da Universidade Federal do Paraná, Hospital Universitário Cajuru, Hospital Universitário Evangélico de Curitiba, Hospital Cruz Vermelha, Santa Casa de Misericórdia e Hospital Pequeno Príncipe. Além dos hospitais, foram escolhidos para realização das entrevistas o Ambulatório da Aliança Saúde, que drena uma grande quantidade de pacientes das unidades básicas de saúde e também a Rua XV de Novembro, onde circula por dia um número amplo de pessoas.

A pesquisa buscou abranger diferentes grupos de entrevistados, como a população leiga, médicos e outros profissionais da área da saúde atuantes em hospitais (fisioterapeutas, enfermeiros, auxiliares de enfermagem e nutricionistas).

O trabalho baseou-se na coleta de dados através de um questionário padronizado para obtenção de quesitos como: idade, sexo, profissão e escolaridade e perguntas com respostas "sim", "não" e "não sei" que abordaram conhecimentos específicos da doação de córneas com as principais dúvidas e as causas de não-doação.

\section{RESULTADOS}

No total, 588 pessoas responderam o questionário, sendo 313 leigos, 157 profissionais da saúde e 118 médicos. Desse total, 94,4\% são a favor da doação de córneas, sendo 91,3\% dos leigos, 96,1\% dos profissionais da saúde e $100 \%$ dos médicos (Figura 1). Dos leigos,

Figura 1. Gráfico do número de entrevistados a favor da doação de córneas

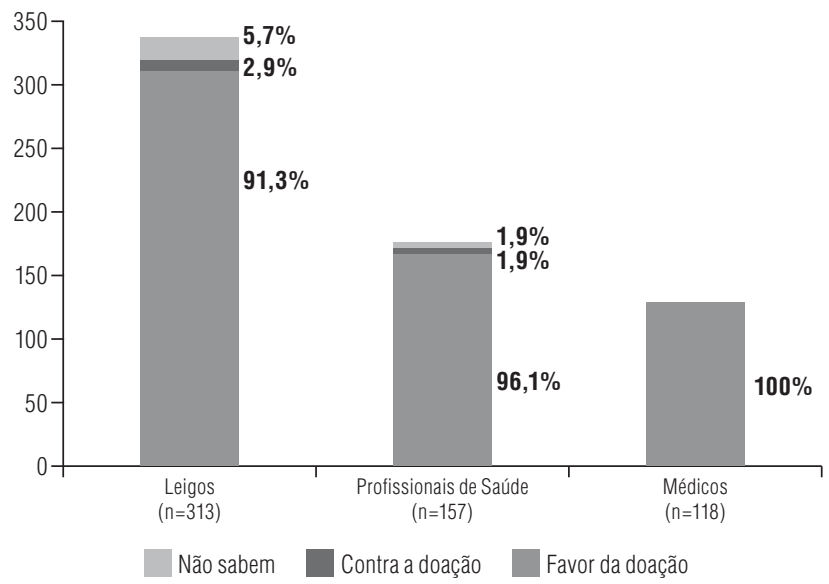


1056 Clotilde Druck Garcia, João Carlos Goldani, Jorge Luis Neumann, Roberto Chem (in memorian), Eduardo Chem, Jose de Jesus Camargo, Fernando Lucchesi, Dario Frota, Italo Marcon, Alexandre Marcon, Ajácio Brandão, Antonio Kalil, Santo Pascoal Vitola, Viviane Barros Bittencourt, Sergio Hausen, Lúcia Elbern, Elizabeth Castro, Adriane P Barboza, Elizete Keitel, João Rafael Victor Schmitt, Valter Duro Garcia

Figura 2. Gráfico do número de entrevistados que doaria a suas córneas

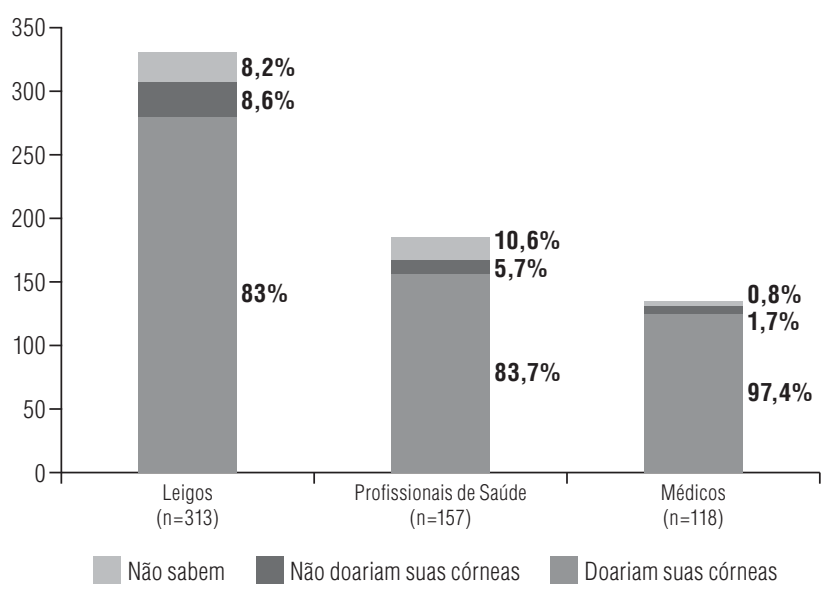

$83 \%$ doariam suas córneas, frente a $83,7 \%$ dos profissionais da saúde e 97,4\% dos médicos (Figura 2).

Quanto à correlação entre o grau de escolaridade entre leigos e profissionais da saúde na decisão ou não de doar suas córneas, obteve-se dos doadores do primeiro grupo 103 pessoas $(39,5 \%) \mathrm{com}$ $1^{\circ} \mathrm{Grau}, 113(43,3 \%)$ com $2^{\circ} \mathrm{Grau}$ e $45(17,2 \%)$ com $3{ }^{\circ} \mathrm{Grau}$. Dos 27 leigos que não doariam suas córneas, $16(59,3 \%)$ tinham o $1^{\circ} \mathrm{Grau}$, $10(37,0 \%)$ o $2^{\circ} \mathrm{Grau}$ e um $(3,7 \%)$ o $3^{\circ} \mathrm{Grau}$. Dos 132 profissionais da saúde favoráveis à doação de suas córneas, cinco $(3,8 \%)$ tinham o $1^{\circ} \mathrm{Grau}, 73(55,3 \%)$ o $2^{\circ} \mathrm{Grau}$ e $54(40,9 \%)$ o $3^{\circ} \mathrm{Grau}$. Desse grupo obtiveram-se 10 profissionais que não doariam suas próprias córneas, sendo oito $(80 \%)$ com $2^{\circ} \mathrm{Grau}$ e duas $(20 \%)$ com o $3^{\circ} \mathrm{Grau}$.

Quando as perguntas subjetivas deram lugar a questões de conhecimento, observou-se alta taxa de dúvida dos entrevistados. Questões como "limite de idade para a doação", "entendimento da função do banco de olhos" e "número de pessoas na fila do transplante" tiveram índices de indecisão de 95,8\%, 28,1\% e $64,8 \%$, respectivamente.

Vinte e sete leigos $(8,6 \%)$ responderam que não doariam suas córneas, sendo que 51,8\% alegaram ter medo de possível negligência no tratamento pelo fato de ser doador, e 37\% acreditavam que a doação alteraria sua aparência. Vinte e seis leigos $(8,2 \%)$ ficaram em dúvida sobre a doação ou não de suas córneas, sendo que $76,9 \%$ responderam que o medo foi o motivo principal, e $23,1 \%$ por acreditarem na alteração estética.

Nove profissionais de saúde $(5,7 \%)$ responderam que não doariam, sendo sete deles $(77,8 \%)$ por medo e dois $(22,2 \%)$ por acreditar que ocorra modificação estética.

Apenas dois médicos (1,7\%) negariam a doação de suas córneas. Embora tenham conhecimento da não alteração da aparência pela captação do órgão, ambos referiram-se ao medo.

Questionou-se quanto à autorização da doação de córnea de algum familiar, tendo uma aprovação de 84,1\% dos entrevistados. Destes, mostraram-se favoráveis $79,8 \%$ dos leigos, $83,4 \%$ dos profissionais de saúde e $96,6 \%$ dos médicos.

Quando os grupos foram abordados sobre a quantidade de pessoas que aguardam na fila para o transplante, $93 \%$ do total não sabiam responder. Dos leigos, $95,8 \%$ não tinham a informação, frente a $91 \%$ dos profissionais da saúde e $88,1 \%$ dos médicos.
Para a pergunta sobre a necessidade de se ter a mesma cor de olhos entre o doador e o receptor, obteve-se uma taxa de 143 pessoas $(24,3 \%)$ que não souberam responder, sendo que dessas, $27,9 \%$ eram profissionais da saúde e $7,6 \%$ eram médicos. Isso retrata uma carência no fornecimento de dados para futuros candidatos a doações.

Quanto ao questionamento da possibilidade de crianças serem doadoras, dos 588 entrevistados, 40,9\% responderam afirmativamente. Do grupo médico, $29,6 \%$ não sabiam informar. Em relação ao limite de idade para ser doador, apenas 137 pessoas $(23,2 \%)$ conheciam a existência desse limite.

Em relação ao procedimento a ser adotado quanto ao desejo de um familiar ou paciente de doar as córneas, dos profissionais de saúde e médicos entrevistados sobre o assunto, 73,2\% e 33,8\%, respectivamente, não sabem como manejar os doadores.

Perguntas que abordaram um conhecimento mais técnico e específico, como "quanto tempo após o óbito os tecidos podem ser retirados" e "tempo de duração do procedimento" foram feitas aos médicos. Dos 118 entrevistados, 66,9\% não sabiam do tempo necessário para remoção da córnea e tampouco a duração da retirada $(67,7 \%)$.

Quanto à solicitação de alguma doação, apenas 11,8\% dos médicos afirmaram já tê-la feito.

Sobre a existência de contraindicação para o procedimento, 17,7\% responderam que não haveria e $38,9 \%$ não souberam informar sobre o tema.

Apenas 27,9\% dos médicos afirmaram sentir-se aptos a responder dúvidas de familiares sobre o processo de doação de córneas. Em vista disso, 89,8\% sentiam necessidade de ampliar seus conhecimentos sobre doação de córneas. Em contrapartida, dos $10,1 \%$ restantes que não desejavam aumentar a informação sobre o processo de captação de órgãos, 1,7\% não se achavam aptos a sanar possíveis dúvidas.

\section{DISCUSSÃO}

A demanda de doações de córnea tem crescido muito nos últimos anos, em razão do investimento nas perspectivas de tratamento, bem como do uso de córneas sob forma terapêutica. ${ }^{8}$

Não há dúvidas de que a deficiência universal de doadores de órgãos é o obstáculo mais importante na provisão de transplantes a diversos pacientes.

Quando os entrevistados foram questionados se seriam favoráveis à doação de córneas, $100 \%$ dos médicos responderam que sim, seguido de $96,1 \%$ dos profissionais da saúde e $91,3 \%$ dos leigos. No entanto, quando interrogados se doariam suas córneas, apenas 97,4\% dos médicos, $83,7 \%$ dos profissionais da saúde e $83 \%$ dos leigos afirmaram que sim. Embora não haja diferença estatisticamente significante entre as respostas dos médicos $(\mathrm{p}=0,148$, Teste de Qui-quadrado relevante para $p<0,05$ ) considerando o acervo de informações conquistado ao longo da grade curricular, observa-se certa incoerência nas respostas, já que nem todos que defendem essa ação aceitariam doar suas córneas.

Quanto ao impacto da escolaridade em relação à doação das próprias córneas, há tendência à significância estatística na associação entre escolaridade e doação entre leigos (Teste de Qui-quadrado, $\mathrm{p}<0,05$, obtendo-se resultado de $\mathrm{p}=0,069)$. Já com relação aos profissionais de saúde, não há correlação estatística significante $(\mathrm{p}=0,301)$. 
Embora exista maior percentual de não doação de córneas entre leigos de $1^{\circ} \mathrm{Grau}(59,3 \%)$, o percentual de entrevistados com $3^{\circ} \mathrm{Grau}$ que responderam afirmativamente para doação de córneas ainda é menor $(17,2 \%)$ do que o percentual de leigos doadores com $1^{\circ} \mathrm{Grau}$ $(39,5 \%)$ e $2^{\circ} \mathrm{Grau}(43,3 \%)$.

A lista de espera para transplante de córnea no primeiro semestre de 2009 no Brasil era de 20.275 córneas, sendo que somente no Paraná esse número ultrapassava 1322 córneas. Quanto aos transplantes realizados no Brasil nesse período, foram 6151 procedimentos, ficando o Paraná com 507. O total de transplantes de córneas no Brasil corresponde a cerca de $75 \%$ de todos os transplantes de órgãos realizados no país. ${ }^{9}$

Por causa da extensa lista de espera para transplante de córnea, o Ministério da Saúde decidiu investir na implantação de Bancos de Tecidos Oculares. Assim, em setembro de 2001 foi instituído o Programa Nacional de Implantação de Bancos de Tecidos Oculares, que objetivava gerar as condições necessárias para implantação de 30 bancos de tecidos oculares distribuídos em todo país. A meta era ampliar a captação de córneas para fins de transplante, encurtar o tempo de espera em fila, e, com isso, o aumentar significativamente o número de transplantes de córnea realizados no Brasil. ${ }^{10}$ Pelos dados obtidos nesta pesquisa, $65 \%$ dos leigos entrevistados não sabiam o que era um Banco de Olhos, seguido de $37 \%$ dos profissionais de saúde e de $13,5 \%$ dos médicos. Isso revela carência da propagação de transplantes corneanos. Quando se compara a publicidade dada a outros setores da medicina, o transplante de córnea não é muito explorado, mas é fator determinante na qualidade de vida das pessoas que dele necessitam.

A deficiência no conhecimento quanto ao procedimento observada nas perguntas sobre modificação da aparência do doador, necessidade de ter a mesma cor de olho, bem como os motivos para a não-doação evidenciou-nos a necessidade de programas de divulgação do transplante de córneas, para que conceitos inadequados não sejam impedimento ao aumento do número de doadores, assim como revelam Basu et al ${ }^{11} \mathrm{em}$ seu trabalho.

Entre os não doadores, $51,8 \%$ dos leigos afirmaram que o medo de possível negligência no tratamento pelo fato de ser doador motivouos a recusar. Esse dado é semelhante ao encontrado por Rodrigues et al, ${ }^{2} \operatorname{com} 53 \%$ de rejeição, sendo o medo e a insegurança quanto ao destino do órgão doado os principais motivos da recusa.

Dos médicos entrevistados, 17,8\% responderam que não há contraindicação do procedimento de transplante e 39\% não sabiam responder. Na literatura, foram citadas razões pelas quais córneas não são captadas para doações tais como: contraindicações médicas, oposição da família durante a abordagem ou puramente problemas logísticos. ${ }^{12}$

Neste estudo evidenciou-se uma deficiência no processo de triagem para o êxito da captação de córnea, pois $73,2 \%$ dos profissionais de saúde e $33,8 \%$ dos médicos não sabiam definir quais eram os procedimentos a ser adotados caso um familiar ou paciente desejasse doar suas córneas.

Das 588 pessoas abordadas, $84,1 \%$ autorizariam a doação de algum membro da família. O estudo publicado por Loewenstein ${ }^{3}$ em 1991 confirmou que o fato das pessoas autorizarem a doação de órgãos em cartões de doação ou carteira de motorista estimularia a reflexão da família e permitiria que a decisão dos familiares levasse em conta a vontade do ente falecido.

O Banco de Olhos do Hospital das Clínicas da Faculdade de Medicina de Ribeirão Preto atua por busca ativa desde 1995. O funcionário do controle de leitos do hospital comunica o óbito de algum paciente a um dos funcionários da equipe de abordagem, que então entra em contato telefônico com um dos familiares e, no caso da aceitação de doação, leva o documento à casa da pessoa para ser assinado. Além de atuarem nos hospitais, atuam ainda na funerária Campos Elíseos, no IML (Instituto Médico Legal) e no Serviço de Verificação de Óbito. Tanto os funcionários da abordagem quanto os do controle de leitos recebem incentivos proporcionais ao êxito na busca ativa; além disso, a abordagem é feita em 100\% dos óbitos de maiores de dois anos. Essa política de abordagem foi responsável pelo aumento progressivo do número de doações de 120 doações/ano, até 1995, para 1.097 em 2004. ${ }^{13}$ Acreditamos que a agilidade dos processos numa instituição como o Banco de Olhos é necessária, tendo em vista que a preservação da vitalidade e qualidade dos tecidos é também mantida em função do tempo. ${ }^{14}$ Esses dados revelam que a integração dos serviços, divulgação de informações e motivação de pessoas e profissionais da área médica corroboram para que a recuperação visual não tenha como fator limitante a falta de doadores.

Segundo Mack et al, ${ }^{15}$ dois dos obstáculos mais importantes no processo de doação foram a não procura de doadores e a falência na abordagem. A não procura, segundo aqueles autores, está relacionada à educação escassa dos profissionais das áreas de saúde, inclusive os de terapia intensiva, já que esta é uma das principais fontes de doadores em potencial.

No presente estudo, todos os médicos, isto é, $100 \%$ dos abordados, mostraram-se favoráveis à doação de córneas, embora apenas 11,8\% já haviam realizado alguma requisição. A falta de solicitação pelos médicos intensivistas é uma importante causa de não-doação tanto por desconhecimento quanto por falta de orientações básicas. ${ }^{16,17}$ Dados semelhantes foram encontrados por Rodrigues et al, ${ }^{5}$ em que todos os médicos que se disseram favoráveis à doação, considerando que apenas $57 \%$ destes já haviam efetivado um processo de doação.

Neste trabalho observou-se que $65,2 \%$ dos médicos não se acham aptos para explanar sobre informações básicas a respeito do transplante de córnea e 6,7\% não sabem informar a respeito. Ainda, $90,7 \%$ afirmaram sentir necessidade de obter mais informações e atualizações sobre o processo de doação.

Para diminuir a grande disparidade existente hoje entre o número de doadores em potencial e o número real de doações, torna-se necessária a criação e realização de campanhas periódicas de esclarecimento, bem como profissionalização das equipes de abordagem com intenso treinamento. Sem o suporte da população geral e sua vontade para doar não haveria órgãos para transplantar. Deve ficar claro, entretanto, que o canal mais adequado para atingir a opinião pública é a mídia. Encontros periódicos com jornalistas e líderes de opinião em transplantes consistem em abordagens pragmáticas para influenciar e educar a mídia em assuntos relacionados a transplantes. Idéias errôneas devem ser discutidas abertamente e, ao mesmo tempo, enfatizando os aspectos positivos de salvar vidas por meio da doação de órgãos e transplantes.

\section{CONCLUSÃO}

Observou-se que ainda há pouca informação sobre transplante de córneas, mesmo entre médicos e profissionais de saúde. Sugere-se focar na profissionalização das equipes de abordagem, a fim de aumentar a captação e o número de transplantes de córnea, além de estimular campanhas de conscientização da população. 


\section{ABSTRACT}

The corneal transplant is now the most common type of tissue transplant, and it has been growing each year in Brazil. However, there is a lack of knowledgeable donors, resulting from misinformation on part of the professionals in the health field. Purpose: To assess the knowledge the laity, health professionals and medical doctors on the cornea donation process; they were argued aiming to identify possible flaws in the reception process. Methods: Along a Cornea Donation Campaign developed in Curitiba-PR, medical doctors, health professionals and laity people were asked to answer a survey with subjective knowledge on the cornea donation. Results: An amount of 588 people responded to the questionnaire, being 313 laymen, 157 health professionals, and 118 physicians. From that total, 94.4\% support the cornea donation, being $91.3 \%$ of the laity, $96.1 \%$ of the health professionals, and $100 \%$ of the medical doctors. Among the laity, $83 \%$ would donate their corneas compared to $83.4 \%$ of health professionals and $97.4 \%$ of medical doctors. When subjective questions were replaced by knowledge questions, there was a high rate of in doubt respondents. Questions such as "age limit for donation," "understanding the function of the eye bank" and "amount of people waiting for a transplant" had indeterminate rates of $95.8 \%, 28.1 \%$ and $64.8 \%$, respectively. Conclusion: It was observed that there is a deficiency of information on the cornea transplantation, even among medical doctors and health professionals. It is suggested to focus on instructing the professional approach team in order to increase both the cornea uptake and the amount of corneal transplants, as well as to stimulate informative campaigns for the population.

Keywords: Cornea, Corneal Transplantation, Directed Tissue Donation, Knowledge.

\section{REFERÊNCIAS}

1. Farge EJ, Silverman ML, Khan MM, Wilhelmus KR. The impact of state legislation on eye banking. Arch Ophtalmol.; 1994;112:180-5.

2. Rodrigues AM, Sato EH. Conhecimento e atitude da população do Hospital São Paulo sobre doação de córneas . Arq. Bras. Oftalmol. 2002;65(6):637-40.

3. Loewenstein A, Rahmiel R, Varssano D, Lazar IM. Obtaining consent for eye donation. Isr J Med Sci. 1991;27(2):79-81.

4. Ishay R. Eye donation - how to maximize procurement. Isr J Med Sci.1991;27:89-91.

5. Rodrigues AM, Sato EH. Entendimento dos médicos intensivistas sobre o processo de doação de córneas . Arq. Bras. Oftalmol. 2003;66(1):29-32.

6. McGough EA, Chopek MW. The Physician's role as asker in obtaining organ donations. Transplant Proc.1990;22:267-72.

7. Espídola RF, Rodrigues BA, Penteado LT, Tan-Ho G, Gozzan JOA, Freitas JAH. Conhecimento de estudantes de medicina sobre o processo de doação de córneas. Arq. Bras. Oftalmol. 2007;70(4):581-84.

8. Hayashi S, Sato EH, Freitas D, Lottenberg CL, Ferraz JM, Nose W. Transplante terapêutico em úlceras de córnea bacterianas ativas. Arq Bras Oftalmol. 1991;52:73-80.

9. Saude.gov.br [sítio na internet] Brasília: Ministério da Saúde; 1997 [atualizada constantemente; acesso em 2007 Jan 27]. Disponível em: http://portal.saude.gov.br/ portal/aplicacoes/noticias/default.cfm?pg=dspDetalheNoticia\&id_area=124\&CO_ NOTICIA $=1975$
10. Sistema Nacional de Transplantes [sítio na Internet] Brasília: Ministério da Saúde; 2005. [citado 2005 Jun 12]. Disponível em: http://tr2001.saude.gov.br/transplantes/ integram.htm

11. Basu PK, Hazariwala KM, Chipman ML. Public attitudes toward donation of body parts, particulary the eye. Can J Ophthalmol. 1989;24:216-20.

12. Delbosc B, Boissier F. [French Directory of Eye Banks. Report on activities during 1993-1997]. J Fr Ophtalmol. 1999;22(2):180-5.

13. Farias RJM, Sousa LB. Impacto do marketing dos processos de divulgação nas doações de córneas a um banco de tecidos oculares humanos e avaliação do perfil socioeconômico de seus doadores. Arq. Bras. Oftalmol. 2008;71(1):28-33.

14. Adán CBD, Diniz AR, Perlatto D, Hirai F, Sato EH. Dez anos de doação de córneas no Banco de Olhos do Hospital São Paulo: perfil dos doadores de 1996 a 2005. Arq. Bras. Oftalmol. 2008;71(2):176-81.

15. Mack JR, Mason P, Mathers WD. Obstacles to donor eye procurement and their solutions at the University of lowa. Cornea 1995;14:249-52.

16. Alves MR, Crestana FP, Kanatami R, Cresta FB, José NK. Doação de córneas: opinião e conhecimento de médicos intensivistas do Complexo Hospital das clínicas da Faculdade de Medicina da Universidade de São Paulo. Rev Med (São Paulo). 1997;76:315-19.

17. Gonzales SZ, Mais M, Vicente LS, Arrata KM, Kormann RB, Moreira H. Papel dos médicos intensivistas no processo de doação de córnea na cidade de Curitiba. Arq. Bras. Oftalmol. 1996;59(5):507-10. 